\title{
Television News and Fear: A Child Survey
}

\author{
JULIETTE H. WALMA VAN DER MOLEN, \\ PATTI M. VALKENBURG \\ and ALLERD L. PEETERS
}

\begin{abstract}
Using telephone interviews among a random sample of 537 Dutch children aged 7-12 years old, we investigated (a) the prevalence of fear reactions to television news among younger and older children and among boys and girls, (b) what types of news items children in different age and gender groups refer to as frightening, and (c) whether children's fear reactions to regular adult television news differed from their fear reactions to a special children's news program. Overall, $48.2 \%$ of the children who reported watching the adult or children's news programs, reported fear reactions to adult news, while $32.6 \%$ reported fear of children's news content. For both types of news programs, younger children and girls more often reported fear than older children and boys did. The most prevalent fear-inducing news content categories were (a) interpersonal violence, (b) fires, accidents, and disasters, and (c) visual depictions of the consequences of violence.
\end{abstract}

Keywords: children, media, fear, fright reactions, TV news, children's news

\section{Introduction}

News constitutes a substantial part of the television diet of both American and European school-aged children (Children Now, 1994; Peeters and Valkenburg, 1998). Most children in the highest grades of elementary school watch the news on television at least several times a week (Children Now, 1994; Peeters and Valkenburg, 1998), whereas they much less frequently use alternative news sources such as newspapers or radio news (Comstock and Paik, 1991). The reasons for children's relatively frequent exposure to television news are probably twofold. First, in most countries, television news is broadcast around the clock, which may enhance the chance that children are exposed to televised news images 
(Walma van der Molen and van der Voort, 2000). Second, even if children choose not to watch the news themselves, they may still be confronted with it when their parents are watching (Cantor and Nathanson, 1996).

Television news has become increasingly violent and graphic in the past decades (Johnson, 1996; Slattery and Hakanen, 1994). Several authors have pointed out that exposure to violent television news may lead to enduring emotional reactions in children, such as fear or concerns about the chance of being victimized (e.g., Cantor, 1998). Interestingly, however, very little empirical research has been conducted regarding the emotional effects of violent television news so far. Hundreds of studies have investigated the impact of violent media content on children (Paik and Comstock, 1994), but the vast majority of these studies focused on the effects of media violence on aggressive behavior. In addition, of the studies that did address children's media-induced fright reactions, most focused on fears induced by fictional television content (e. g., Cantor and Sparks, 1984; Spirek, 1993), rather than on fears induced by real-life violence depicted in television news. The main goal of the present survey study, therefore, was to investigate the prevalence of children's fear reactions to violent television news.

To our knowledge, only one earlier survey study, conducted by Cantor and Nathanson (1996), investigated the prevalence of children's fear reactions to violent television news. This telephone survey showed that $37 \%$ of children aged 4 to 12 years old sometimes experienced fear when watching the news on television. Our survey was in part similar to Cantor and Nathanson's study. Like Cantor and Nathanson, we conducted a telephone survey in which we explored how often children experience fear when watching television news and what types of news stories are particularly frightening to them. We also investigated potential differences between boys and girls and between children of different age groups.

Our survey study differed from Cantor and Nathanson's (1996) study in two respects. First, we interviewed children about their fears induced by television news, whereas Cantor and Nathanson interviewed parents about their children's fears. Although it might be more reliable to conduct telephone interviews among parents rather than children, it remains unclear whether parents are able to make valid estimates of their children's fears. In a Dutch survey among children and parents, in which children's fright reactions to television were investigated, the child reports revealed significantly more fright reactions than the parent reports (Valkenburg, 1997). Parents might underestimate their children's fears because they may be unaware of their children's experiences with frightening television content. The prevalence of fear reactions induced by 
television news should, therefore, also be established through interviews among children.

The second way in which our study differed from Cantor and $\mathrm{Na}$ thanson's (1996) study was that we not only investigated children's fears induced by regular adult television news, but also the fears induced by television news that is designed for a child audience. The present survey study was conducted in the Netherlands, where, since 1980, a children's news program (Jeugdjournaal) is broadcast daily between 6.45 and 7.00 p.m. This news program is designed specifically to render the main news comprehensible to children between 9 and 12 years of age.

The producers of the Dutch children's news often debate whether they should cover violent news events or not (see Créton, 1994, for an overview). On the one hand, their main goal is to select news topics solely on the basis of their news value, which does imply occasional coverage of violent events. For example, during the Gulf War, the producers decided to broadcast the videotaped images of the British pilots that had been taken hostage by Iraq. Although everyone realized that these pictures were shocking, they were broadcast because they were main world news at that time. On the other hand, the producers of the children's news take care to ensure that children will not be too upset by watching the children's news. First, they make an effort to explain the seriousness of a news event without showing the most graphic film footage (Créton, 1994). Second, to offset possible harmful effects of a violent news topic, a 'heavy' news item is always succeeded by a 'light' news item.

Although the policy of the children's news is to prevent fright reactions, anecdotal evidence suggests that children may nevertheless become frightened by this news program (see Valkenburg, 1997). In the present survey study, we explored how many children experience fright reactions to the children's news. We also compared the prevalence of fright reactions to the children's news with children's fear of adult news. Finally, we investigated whether children refer to different fear-provoking news content in the case of the children's news than they do in the case of adult news.

\section{Gender and developmental differences in children's fright reactions to media content}

Previous research on television-induced fear reactions has repeatedly shown both gender and developmental differences in children's television-induced fear responses (Cantor, 1996; Valkenburg, Cantor and Peeters, 2000). As for gender, the majority of the studies found that females report more fear of violent media content than males do (see Peck, 1999, for a meta-analysis). However, most of these studies focused 
on fictional rather than real-life television violence. Gender differences in children's fear reactions to violent news are relatively unexplored. One aim of the present study, therefore, was to investigate whether boys and girls differ in their reported fears of violent news content.

A number of developmental effects have been observed in children's emotional reactions to violent media content. A first developmental difference is that younger children are more responsive to explicit visual depictions of a threat than older children (e.g., Cantor and Sparks, 1984). Research on cognitive development has indicated that, in general, young children react to televised stimuli predominantly in terms of their perceptible characteristics, while older children tend to respond more to conceptual components of the televised stimulus, such as the perpetrator's motives or potential future threats (Bruner, 1966; Flavell, 1963; Melkman, Tversky and Baratz, 1981).

This tendency of younger children to respond more strongly to perceptible characteristics of frightening media content was also observed by Cantor and Nathanson (1996), who found that fear of news items about interpersonal violence increased with age, while fear of news items about natural disasters decreased with age. Cantor and Nathanson argued that news stories about natural disasters usually provide many explicit images of devastation, whereas news about interpersonal violence often does not show details of the violent event. This might be the reason why younger children are more often frightened by natural disasters, while older children, who are less perceptually dependent (Bruner, 1966), might become more easily frightened by news items about interpersonal violence. In the present study, we examined whether these developmental differences would again appear in our sample of school-aged children.

A second developmental effect is that older children become more easily frightened by media depictions involving abstract threats than younger children (Cantor, 1996). Abstract threats, such as potential nuclear wars or environmental problems, may be less frightening to younger children because they are too difficult for them to comprehend. This notion is consistent with theories of cognitive development (e.g., Flavell, 1963), which indicate that the ability to think abstractly emerges relatively late. Studies that have found developmental differences in children's fear of abstract threats have usually focused on fictional content (e. g., Cantor, Wilson and Hoffner, 1986). In the present study, we explored whether younger and older children differ in their references to abstract fear-provoking television news content, such as environmental pollution or other threats that may affect children's future.

A final developmental difference in children's television-induced fright reactions is related to children's increasing role-taking ability and their growing ability to express empathy with other's joy or distress. Eisenb- 
erg-Berg and Mussen (1978) defined empathy as the ability to take the perspective of another and feel what that person feels. Several studies (e. g., Hoffman, 1976; Eisenberg-Berg and Mussen 1978) have indicated that starting at about the age of nine, children increasingly empathize with the general condition of others and with 'world problems' such as wars and suffering in general. This growing concern for those less fortunate than oneself could prompt older school-aged children to express more fears of news about war and suffering than younger children. In addition, older children might be more inclined to imagine themselves to be in the same unfortunate situation as the people depicted on television, or to express concern that the same violent event would happen to them. In the present study, we investigated whether younger and older children differ in their reference to fear induced by news about war and suffering. In addition, we analyzed whether younger and older children differ in their expressed concern that a violent news event could happen to them.

\section{Research Questions}

Because the present study represents a first attempt to explore children's self-reported fears induced by television news, research questions rather than specified hypotheses were formulated. Our first research question is:

$\mathrm{RQ}_{1}$ : What is the prevalence of fear reactions to television news among Dutch children between the ages of 7 and 12 years and do these reactions differ for (a) younger versus older children, (b) boys versus girls, and (c) adult versus children's news programs?

We also explored what types of news items children refer to as frightening. Because previous studies of children's television-induced fears have shown gender and developmental differences in the types of media content that induce fear, our second research question asked:

$\mathrm{RQ}_{2}$ : To what specific fear-provoking news content do children refer and do their responses differ for (a) younger versus older children, (b) boys versus girls, and (c) adult versus children's news programs?

\section{Method}

\section{Sample}

In January 1998, the Audience Research Department of the Netherlands Broadcasting Corporation carried out telephone interviews among a 
random sample of 537 Dutch children between the ages of 7 and 12 years. The interviews were carried out in the afternoon and evening hours. The sample was drawn from a nationally representative data bank of families who had agreed to participate in regular telephone interviews. The children who were surveyed were therefore familiar with telephone interviews. In the past years, we have conducted several child telephone surveys (e. g., Valkenburg, 1997; Valkenburg, Cantor and Peeters, 2000; Valkenburg, Walma van der Molen and Peeters, 2001). It is our experience that, especially when it comes to personal opinions and emotions, socially desirable responses are less likely to occur when children are interviewed on an individual basis on the phone than when they are interviewed in a class-room setting.

From each family, one child was randomly chosen to participate in the survey. Half of the children $(\underline{\mathrm{n}}=269)$ were boys, the other half $(\underline{\mathrm{n}}$ $=268$ ) were girls. The sample included approximately an equal number of children in each age group. Because the Dutch children's news is developed specifically for children aged 9 to 12 years, we grouped our sample into two age groups: 7 - to 8 -year-olds $(\underline{\mathrm{n}}=168)$ and 9 - to $12-$ year-olds $(\underline{\mathrm{n}}=369)$.

\section{Procedure}

Children were first presented with some filler questions about their television viewing and their favorite programs to make them feel at ease with the telephone interviewer. Then, each child was systematically presented with two sets of questions, one pertaining to the children's news and one pertaining to adult news. The interviewer started by asking how many days a week the children would watch the children's news program. If the child indicated that s/he watched the children's news at least once a week, the child was asked whether something in the children's news had ever scared him or her. If the child responded positively to this question, s/he was presented with an open-ended question about what specific content in the children's news had caused this fear. After completing the questions about the children's news, the telephone interviewer asked the same set of questions in regard to the adult news. Children's responses to the open-ended questions were written down verbatim.

\section{Coding Categories}

To analyze children's open-ended responses about what type of news content had caused their fear, we set up a series of coding categories. The development of these categories was based on an overview of all children's open-ended responses, that is, responses about children's news 
content as well as adult news content. Because many children referred to multiple news events or a single event that could fall into more than one content category, each coding category was coded as being present or absent in the child's open-ended response. The categories were therefore not mutually exclusive. The coding was carried out by two independent judges. Intercoder reliabilities, as measured by Cohen's kappa, were satisfactory (all kappas $>$.85). We identified the following seven coding categories:

Interpersonal violence. This category included references to violence such as killing, fighting, shooting, kidnapping, and physical or sexual abuse. The violence could occur between individuals and/or groups, and between strangers and/or acquaintances. This category excluded violence in the context of a war.

Fires, accidents, disasters. This category included references to news events such as house fires, forest fires, car crashes, plane crashes, and natural disasters such as tornadoes, earthquakes, and floods.

War and suffering. This category included references to news about wars, famine, poor people, and people suffering from diseases.

Harm against children. This category included references to violence in which a child was specifically mentioned as the victim.

Burglary and thieves. This category included references to news about burglary, thieves, and felons escaping from prison.

Harm against animals. This category included references to people hurting animals or animals suffering from diseases. It excluded references to news about animals harming people or news about the extinction of animals due to environmental problems.

Environment and future. This category included references to news about environmental problems, such as pollution, and references to future threats, such as nuclear wars or the ill use of genetic manipulation.

In response to the open-ended question about what specific news content had caused their fear, many children not only referred to specific news events, but also to explicit visual depictions of the consequences of violent events, such as blood or dead bodies. In order to assess these references, the following coding category was developed:

Reference to explicit visuals. This category included all references to explicit graphic depictions of the physical and emotional consequences of violence, such as blood, dead bodies, and people screaming or crying.

Apart from their reference to specific news events or their reference to explicit visuals, some children specifically mentioned that a violent news event had scared them because they could imagine themselves to be in the same violent situation, or because they were afraid that the same event might also happen to them. To assess these concerns, the following coding category was developed: 
Reference to own situation. This category included all references to the possibility that a violent event could happen to the children themselves, to one of the child's friends or relatives, or to the child's neighborhood.

\section{Results}

\section{Prevalence of news-induced fear}

Our first research question asked how frequently Dutch children between the ages of 7 and 12 experience fear reactions to television news and whether these reactions differ for (a) younger versus older children, (b) boys versus girls, and (c) adult versus children's news programs.

In order to make valid estimates of the prevalence of children's fear reactions to adult and children's television news programs, it is necessary to determine children's viewing frequencies of the two types of news programs. Our results showed that more 9- to 12-year-olds (87.0\%) than 7- to 8 -year-olds $(51.2 \%)$ reported watching the adult news, $\chi^{2}(2, n=$ $537)=84.02, p<.001$. In regard to the children's news, there was no significant difference in the viewing frequencies of younger and older children. Of the 7- to 8-year-olds, $77.9 \%$ reported watching the children's news, and of the 9 - to 12 -year-olds, $81.8 \%$ reported watching the program.

Of the total sample of children who watched the adult news, $48.2 \%$ reported having been frightened by adult news content (see Table 1). Younger children and girls more often reported fear in response to adult news than older children and boys did: $\chi^{2}(1, N=407)=4.35, p<.04$ and $\chi^{2}(1, N=407)=18.58, p<.001$, respectively.

Of the children who reported watching the children's news, $32.6 \%$ reported fear reactions to the content of this program (see Table 1). To analyze whether this percentage differed significantly from the reported fear reactions to the adult news programs $(48.2 \%)$, a Wilcoxon Signed Rank Test for two dependent samples was performed. This test revealed that the children's news caused significantly fewer fear reactions than the

Table 1: Percentages of children reporting fear of adult and children's news content.

\begin{tabular}{llllll}
\hline & $7-8$ years & $9-12$ years & Boys & Girls & Total \\
\hline & $\%$ & $\%$ & $\%$ & $\%$ & $\%$ \\
Fear of adult news & $58.1^{\mathrm{a}}$ & $45.5^{\mathrm{b}}$ & $37.6^{\mathrm{y}}$ & $58.9^{\mathrm{x}}$ & $48.2^{\mathrm{p}}$ \\
Fear of children's news & $43.5^{\mathrm{a}}$ & $27.8^{\mathrm{b}}$ & $27.1^{\mathrm{y}}$ & $38.1^{\mathrm{x}}$ & $32.6^{\mathrm{q}}$ \\
\hline
\end{tabular}

Note: Row differences between ${ }^{\mathrm{a}, \mathrm{b}}$ younger versus older children and ${ }^{\mathrm{x}, \mathrm{y}}$ girls versus boys were significant at least at $p<.05$ level. ${ }^{\mathrm{p}, \mathrm{q}}$ Column differences between the adult and children's news were significant at $p<.001$. 
Table 2: Percentages of younger and older children referring to different fear-provoking adult and children's news content.

\begin{tabular}{|c|c|c|c|}
\hline Reference to news events & $\begin{array}{l}7-8 \text { years } \\
\%\end{array}$ & $\begin{array}{l}9-12 \text { years } \\
\%\end{array}$ & $\begin{array}{l}\text { Total } \\
\%\end{array}$ \\
\hline \multicolumn{4}{|l|}{ Interpersonal violence } \\
\hline Adult news & 40.0 & 50.8 & 48.5 \\
\hline Children's news & 31.0 & 46.5 & 40.7 \\
\hline \multicolumn{4}{|l|}{ Fires, accidents, disasters } \\
\hline Adult news & 34.3 & 21.1 & 23.9 \\
\hline Children's news & $33.3^{\mathrm{a}}$ & $16.9^{\mathrm{b}}$ & 23.0 \\
\hline \multicolumn{4}{|l|}{ War and suffering } \\
\hline Adult news & 14.3 & 22.7 & $20.9^{x}$ \\
\hline Children's news & 11.9 & 15.5 & $14.2^{\mathrm{y}}$ \\
\hline \multicolumn{4}{|l|}{ Harm against children } \\
\hline Adult news & 2.9 & 10.9 & 9.2 \\
\hline Children's news & 14.3 & 9.9 & 11.5 \\
\hline \multicolumn{4}{|l|}{ Burglary and thieves } \\
\hline Adult news & 8.6 & 5.5 & 6.1 \\
\hline Children's news & 9.5 & 5.6 & 7.1 \\
\hline \multicolumn{4}{|l|}{ Harm against animals } \\
\hline Adult news & 5.7 & 3.9 & 4.3 \\
\hline Children's news & 2.4 & 7.0 & 5.3 \\
\hline \multicolumn{4}{|l|}{ Environment and future } \\
\hline Adult news & 0.0 & 1.6 & 1.2 \\
\hline Children's news & 0.0 & 4.2 & 2.7 \\
\hline \multicolumn{4}{|l|}{ Reference to explicit visuals } \\
\hline Adult news & 14.3 & 27.3 & 24.5 \\
\hline Children's news & 21.4 & 25.4 & 23.9 \\
\hline \multicolumn{4}{|l|}{ Reference to own situation } \\
\hline Adult news & 0.0 & 3.1 & $2.5^{\mathrm{y}}$ \\
\hline Children's news & 4.8 & 12.7 & $9.7^{\mathrm{x}}$ \\
\hline
\end{tabular}

Note: Children's answers could fall into more than one category. ${ }^{\mathrm{x}, \mathrm{y}}$ Column and $\mathrm{a,b}$ row differences were significant at $p<.05$ level.

adult news $(z=5.36, N=211, p<.001)$. As was found for adult news content, younger children and girls more often reported fear in response to the children's news than older children and boys did, $\chi^{2}(1, N=433)$ $=10.25, p<.002$ and $\chi^{2}(1, N=433)=6.05, p<.02$, respectively.

\section{References to different fear-provoking adult and children's news content}

Our second research question asked whether there are differences in the references to different types of fear-provoking news content between (a) younger and older children, (b) boys and girls, and (c) adult and children's news programs. In the case of the adult news, 163 children responded to our open-ended question about what type of news content had scared them. In the case of the children's news, 113 responded to 
this question. Table 2 reports the percentages of children who referred to the different types of fear-provoking news content.

Both in the case of the adult news and in the case of the children's news, children most frequently cited interpersonal violence as the cause of their fear. The two other most frequently mentioned fear-provoking news categories in both news programs were (a) fires, accidents, and disasters, and (b) explicit visual depictions of violence, such as blood and dead bodies.

For both the adult and children's news programs, we observed that references to interpersonal violence tended to increase with age, although for both programs this increase only approached significance at the $p=$ .10 level. For both news programs, children's references to fires, accidents, and disasters decreased with age. In the case of the children's news this decrease was significant, $\chi^{2}(1, N=113)=4.02, p<.05$, whereas in the case of the adult news it fell below significance at the $p=.10$ level. None of the other differences between younger and older children were statistically significant. Because we did not find any gender differences in children's references to fear-provoking news content, separate percentages for boys and girls are not included in Table 2 .

Overall, children's reported fright responses to adult versus children's news programs showed very similar patterns. However, there were two exceptions. Wilcoxon Signed Rank Tests showed that children less frequently mentioned news items about war and suffering in the case of the children's news, $(z=2.50, N=77, p<.02)$, whereas they less often referred to their own situation in the case of the adult news, $(z=2.33$, $N=77, p<.03)$.

\section{Discussion}

The main goal of our survey study was to investigate the prevalence of children's fear reactions to television news. We compared children's fear of regular adult television news to their fear of a news program specifically designed for children. In several European countries, such as the United Kingdom, Austria, and the Netherlands, national children's news programs are produced, designed to render the main news comprehensible to school-aged children.

\section{Fear reactions to adult news}

As for the adult news, we observed that $48.2 \%$ of our respondents reported having been frightened by something on the adult television news. This percentage is substantially higher than that reported by Cantor and Nathanson (1996), who found that $37 \%$ of the parents indicated that 
their child had experienced fright reactions to television news. The higher percentage observed in our study could imply that the parents in Cantor and Nathanson's study underestimated their children's fears.

However, upon closer examination, we believe that there is another explanation for the difference in results found in our survey and the one conducted by Cantor and Nathanson (1996). Contrary to Cantor and Nathanson, whose investigation of fear reactions was based on their total sample of respondents, we excluded the children who never watched television news from our analyses. We believe that children's exposure to television news should be taken into account in order to make valid estimates of their fear reactions to this type of program. If we had followed Cantor and Nathanson's procedure and had also included the non-viewers, the percentage of children who experienced fright reactions would have dropped to $36.5 \%$, a value that is very similar to the percentage reported by Cantor and Nathanson.

We also investigated age and gender differences in children's fears. We found that children's fear reactions to television news decreased with age, a result that contradicts Cantor and Nathanson's (1996) study, which showed that children's fear reactions to television news increased with age. This contradictory result might be explained by younger and older children's differential exposure to television news. Our study showed that approximately half of the younger children did not watch adult television news (in comparison to only $13 \%$ of the older children). If we had included those children who never watch adult news in our analyses, children's fright reactions would have increased with age. However, in our opinion, such an analysis would have seriously underestimated younger children's fright reactions to news content.

As for gender, we found that girls reported more fear reactions to adult television news than boys did. This result is in accordance with earlier studies that investigated fear of fictional violent media content (see Peck, 1999, for a review). Although some researchers assume that girls are born with a greater susceptibility to fears, many others believe that the differences between boys and girls are due to differential childrearing practices imposed on boys and girls. Whereas boys are expected to behave in a masculine way, girls are allowed, or sometimes even encouraged, to show their emotions, worries and vulnerabilities (Peck, 1999). Although the majority of studies on children's television-induced fright reactions showed gender differences, Cantor and Nathanson (1996) did not find any differences between the news-induced fear reactions of boys versus girls. We suppose that the absence of a gender effect in their study was due to the fact that they interviewed parents about their children's fear reactions. It may be that parents are less hesitant to admit their sons' fears to an interviewer than the boys themselves are. 


\section{Fear reactions to children's news}

The children in our sample reported significantly fewer fright reactions to the children's news than to adult news. However, despite the producers' efforts to minimize fear, $32.6 \%$ of the children who watched the children's news still reported fear reactions. Our 9- to 12-year-olds, who are the target audience of the children's news, less frequently reported fright reactions than the 7- to 8-year-olds did. Although the children's news is not meant for 7 - to 8 -year-olds, $77.9 \%$ of this age group reported watching the program, and $43.5 \%$ indicated that the program had sometimes scared them. In our view, this result indicates that parents and educators should be more reluctant in allowing younger children to watch this program.

\section{Children's reactions to specific news content}

Apart from investigating possible differences in the general prevalence of news-induced fear, we also investigated what specific news content children in different age groups experienced as frightening. The categories of news content that children most often cited as the cause of their fear were (a) interpersonal violence, (b) fires, accidents, and disasters, an (c) explicit visual depictions of the consequences of violence. Although the children's news seemed to be less frightening than the adult news, the content categories to which children referred to as sources of their fears were quite similar to those found for the adult news.

Like Cantor and Nathanson (1996), we found that older children more often referred to news events about interpersonal violence, whereas younger children more frequently reported having been frightened by fires, accidents, and disasters. The differences found in our study were less strong than those found in Cantor and Nathanson's study. This is probably the result of the fact that we interviewed 7- to 12-year-olds, whereas Cantor and Nathanson's study reported on fear reactions among 4- to 12-year-olds. Like Cantor and Nathanson, we believe that the age effects found in our study must be attributed to the differential way in which younger and older children react to visual cues. Cantor and Nathanson argued that news stories about natural disasters more often than news stories about interpersonal violence provide explicit images of devastation, and if available, images of the actual event. This could explain why the younger, more perceptually dependent, children reported more fright reactions to news items about fires, accidents, and disasters, whereas the older children more often reported fear of news items about interpersonal violence.

Our results showed some additional differences between younger and older children's reported fears of different news content. However, none 
of these differences were statistically significant. This is probably due to the fact that our exploration of fear-provoking news content was based on children's spontaneous answers to an open-ended question. Because only part of the children in our sample could mention specific frightening news content, our analyses were based on lowered numbers of observations, with the result that they were less powerful (Valkenburg et al., 2000). However, our exploration of children's self-reported fears of specific news content did show some differences between younger and older children that are worth discussing here.

First, older children more often mentioned fear of war and suffering than younger children did. This tendency of older children is consistent with theories on the development of empathy in children, which state that, from around the age of nine, children increasingly empathize with the general condition of others and with problems in the world. Second, only children in the older age group mentioned fear of environmental problems and abstract future problems. Although only a small number of older children referred to this category, it is striking that none of the 7- to 8-year-olds mentioned it as source of their fears. This difference between younger and older children reflects a developmental tendency that is consistent with theories on the development of abstract fears and worries in children.

A comparison of children's references to adult versus children's news content showed two differences in children's fright responses. First, children less frequently referred to war and suffering in case of the children's news than in case of the adult news. This result might be explained by the fact that the Dutch children's news pays less attention to items about war and suffering than regular adult news programs do. The second difference was that children more frequently referred to their own situation in the case of dangers portrayed in the children's news than they did in case of adult news content. This finding is probably the result of the manner in which the Dutch children's news covers news topics. In order to customize the children's news to the needs and experiences of children, many news topics in the children's news are covered from the perspective of children. This approach might induce child viewers to identify with the children portrayed on television, and, as a consequence, to express more concern that the threats or dangers might also happen to them.

\section{Conclusion}

The present study encompassed a first investigation of self-reported fears induced by television news among a random sample of children. Our study revealed some interesting effects that are worth testing in future 
research. Our results showed that a considerable proportion of schoolaged children in the Netherlands experienced fear from watching television news. Despite the observation that television news has become progressively violent and graphic in the past decade (Johnson, 1996; Slattery and Hakanen, 1994), researchers and educators have thus far paid relatively little attention to the harmful consequences of children's television news consumption.

This study made a first attempt to investigate children's fright reactions to the news. Our study focused on the prevalence of fright reactions, and on age and gender differences in fright reactions. Our study did not investigate the processes that underlie children's fright reactions to media content, such as motivations to watch the news, and cognitive and personality factors. Future research should elaborate on our exploratory findings and attempt to investigate the different factors that may mediate or moderate children's emotional reactions to news content.

\section{References}

Bruner, J. S. (1966). On cognitive growth I and II. In J. S. Bruner, R. R. Oliver and P. M. Greenfield (Eds.), Studies in cognitive growth (pp. 1-67). New York: John Wiley.

Cantor, J. (1996). Television and children's fear. In T. M. MacBeth (Ed.), Tuning into young viewers. Thousand Oaks, CA: Sage.

Cantor, J. (1998). Mommy I'm scared: How TV and movies frighten children and what we can do to protect them. San Diego, CA: Harcourt Brace.

Cantor, J. and Nathanson, A. I. (1996). Children's fright reactions to television news. Journal of Communication, 46, 139-152.

Cantor, J. and Sparks, G. G. (1984). Children's fear responses to mass media: Testing some Piagetian predictions. Journal of Communication, 34, 90-103.

Cantor, J., Wilson, B. J. and Hoffner, C. (1986). Emotional responses to a televised nuclear holocaust film. Communication Research, 13, 257-277.

Children Now (1994). Tuned in or tuned out? America's children speak out on the news media. Oakland, CA: Author.

Comstock, G. and Paik, H. (1991). Television and the American child. New York: Academic Press.

Créton, R. (1994). Children's TV news bulletins: Professional perspectives. Unpublished master's thesis, University of Wales, College of Cardiff, Wales, Great Britain.

Eisenberg-Berg, N. and Mussen, P. (1978). Empathy and moral development in adolescence. Developmental Psychology, 14, 185-186.

Flavell, J. (1963). The developmental psychology of Jean Piaget. New York: Van Nostrand.

Hoffman, M. L. (1976). Empathy, role-taking, guilt, and development of altruistic motives. In T. Lickona (Ed.), Moral development and behavior. New York: Holt, Rinehart and Winston.

Johnson, R. N. (1996). Bad news revisited: The portrayal of violence, conflict, and suffering on television news. Peace and Conflict: Journal of Peace Psychology, 2, 201-216. 
Melkman, R., Tversky, B. and Baratz, D. (1981). Developmental trends in the use of perceptual and conceptual attributes in grouping, clustering, and retrieval. Journal of Experimental Child Psychology, 31, 470-486.

Paik, H. and Comstock, G. (1994). The effects of television violence on antisocial behavior: A meta-analysis. Communication Research, 21, 516-546.

Peck, E. (1999). Gender differences in film-induced fear as a function of type of emotion measure and stimulus content: A meta-analysis and laboratory study. Unpublished doctoral dissertation, University of Wisconsin, Madison.

Peeters, A. L. and Valkenburg, P. M. (1998). Het Jeugdjournaal: Nieuws voor kinderen van 10-12 en kinderen van 7-9? [The Children's News: News for children aged 10-12 and children aged 7-9?]. Hilversum, The Netherlands: Netherlands Broadcasting Corporation.

Slattery, K. L. and Hakanen, E. A. (1994). Sensationalism versus public affairs content of local TV news: Pennsylvania revisited. Journal of Broadcasting and Electronic Media, 30, 309-323.

Spirek, M. M. (1993). Parent and child perceptions of strategy effectiveness for reducing children's television-induced fear. Journal of Social Behavior and Personality, $8(6), 51-65$.

Valkenburg, P. M. (1997). Vierkante ogen: Opgroeien met TV en PC [Square eyes: Growing up with TV and PC]. Amsterdam: Balans.

Valkenburg, P. M., Cantor, J. and Peeters, A. L. (2000). Fright reactions to television: A child survey. Communication Research, 27, 82-99.

Valkenburg, P. M., Walma van der Molen, J. H., and Peeters, A. L. (2001). Should news on child homicides be broadcast? Opinions of parents, teachers, and children. Communications: The European Journal of Communication Research, 26, $229-245$.

Walma van der Molen, J. H., and van der Voort, T. H. A. (2000). Children's and adults' recall of television and print news in children's and adult news formats. Communication Research, 27, 132-160. 